\title{
Elektronik Şalter ve Kaçak Akım Röleli Hibrit Bir Sistemin Geliştirilmesi
}

\author{
Development of a Hybrid System with Electronic Switch and Residual Current Relay
}

\author{
Mustafa YAĞIMLI ${ }^{1}$ (D), Ahmet YURTÇU ${ }^{2}$

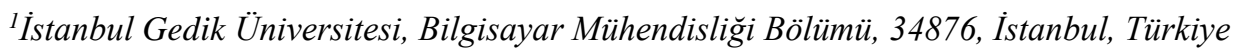

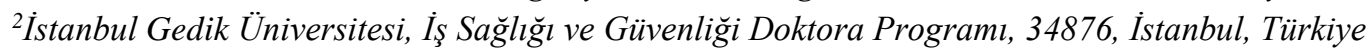

$\ddot{\mathbf{O z}}$

Manyetik alan prensibine göre çalışan geleneksel röleli anahtarlarda; rölenin enerjilenmesi, kontağı çekmesi için geçen süre, yüksek güçlü uygulamalarda kontağın aşırı ısınma sonucu yapışması, oluşacak arklar sonucu yangına sebebiyet vermesi, enerji tasarrufu gibi sorunları mevcuttur. Elektrik çarpmasında hayat kurtarıcı ve yangın tehlikesine karşı kullanılan kaçak akım rölesinde ise rölenin enerjilenip kontağı itmesi ve sistemi enerjisiz bırakmasında geçen sürenin insan hayatının kurtarılmasında nanosaniyeler mertebesinde olması gerekir. Literatürde; elektronik şalter düşük güçlü devrelerde kullanılmıştır. Bu çalışmada, yüksek güçlü devrelerde kullanılmak üzere elektronik şalter ile kaçak akım rölesi hibrit olarak geliştirilmiştir.

Anahtar Kelimeler: Elektronik şalter, devre kesici, sıfir geçiş, hibrit system.

\section{Abstract}

In traditional relay switches working according to the magnetic field principle; The relay has energization, the time it takes to pull the contact, in high-power applications, the contact sticks due to overheating, causing fire due to arcs to occur, and energy saving. In the leakage current relay, which is used to save life and fire danger in electric shock, the time it takes for the relay to energize and push the ignition and to de-energize the system must be in the order of nanoseconds in saving human life. In the literature; the electronic switch is used in low-power circuits. In this study, the electronic switch and leakage current relay have been developed as hybrid for use in high power circuits.

Keywords: Electronic switches, circuit breaker, zero crossing, hybrid system.

\section{GİRIŞ}

Hem günlük yaşam hem de üretim tesisleri için elektrik vazgeçilmez bir enerji türüdür. Hemen hemen her türlü cihazın kullanımı için mutlaka elektrik enerjisi gereklidir. Dünyadaki kalkınmışlık düzeyi ve teknolojik gelişim, elektrik üretimi, elektrikle çalışan aygıtlar ve tüketilen elektrik enerjisi ile doğru orantılı olarak kabul edilir. Elektrik enerjisi insanlık için ne kadar vazgeçilemez ise de gerekli önlemler alınmadığı sürece sonu ölümlere varan kazalara ve ağır makine ve ekipman hasarına sebep olmaktadır. Bu kadar tehlikeli olmasına rağmen günümüzde elektrik enerjisinin kullanılmadığı bir yaşam da düşünülemez [1]. Teknolojilerin baş döndürücü bir şekilde devam ettiği günümüzde özellikle sanayide elektrik enerjisinin önemi de kullanım alanları da her geçen gün giderek artmaktadır. Dolayısıyla elektrik kazalarının sayısında da buna paralel olarak artış olmuştur.

Şu anda yürürlükte olan mevzuatlarımıza göre iş kazası 5510 sayılı Sosyal Sigortalar ve Genel Sağlık Sigortası Kanunu'nun 13. Maddesi'nde ve 6331 sayılı İş Sağlığ 1 ve Güvenliği Kanunu’nun 3. Maddesi'nde kavramsal olarak yer almaktadır. İş kazasının ulusal ve uluslararası yapılan tanımlarda özellikle, çalışanların o an veya sonradan ruh ve beden sağlığına özre uğratan veya ölüme sebebiyet veren bir olay olduğu belirtilmektedir. Sosyal Güvenlik Kurumu (SGK) istatistikleri incelendiğinde ülkemizdeki iş kazalarının öncelikli sebeplerinin arasında elektrikle çalışmaların da geldiği görülmektedir. 2016 yılı SGK istatistiklerine göre 614 "Bir kaynak arkı, kıvılcım veya çakması" iş kazası olmuştur. SGK tarafından oluşturulan bu istatistiklere sadece iş göremezlik ve ölümle sonuçlanan kazalar alınmaktadır. Can kaybına veya yaralanmaya sebep olmayan sadece maddi hasara neden olan veya herhangi bir zararla sonuçlanmayan kazalarda bu sayıya eklendiğinde bu rakamın çok daha yüksek olduğu görülmektedir [2].

Elektrik kaynaklı kazaların birçoğuna elektrik sistemlerinde meydana gelen kaçak akımların neden olduğu bilinmektedir. $\mathrm{Bu}$ nedenle kaçak akım rölesi elektrikte işçi sağlı̆̆ ve güvenliğinin temel unsuru olarak düşünülebilir. Kaçak akım röleleri insan hayatını korumaya yönelik bir unsur olduğundan oldukça önemli ve bir elektrik sisteminde kesinlikle bulunması gereklidir. Ayrıca bir binanın ya da endüstriyel bir tesiste kullanılan tüm 
elektrik sistemlerinin topraklama sisteminin doğru şekilde yapılmış olması kaçak akım rölelerinin doğru çalışmasında oldukça etkilidir [3].

Elektrik uygulamalarında kazalara karşı emniyet, genel olarak cihaz ve tesislerin temel izolasyon yoluyla elde edilmektedir. Fakat temel izolasyondaki arızalar tehlikeli durumlara yol açabilmekte olup, bu gibi durumlar çok yüksek olan gövde akımlarına karşı ilave koruyucu önlemlerin alınması gerektirmektedir [4].

Bu bağlamada yapılan çalışmanın amacı hem yüksek akımlar gerektiren elektrik tesislerinde kullanılan panolarda oluşan elektrik arklarından dolayı meydana gelen kazaları engellemek hem de elektronik olarak çok daha hızlı çalışacak olan bir elektronik şalter ve kaçak akım rölesi tasarlamaktır. $\mathrm{Bu}$ iki işlem önerilen sistemde bütünleşik olarak tasarlanmıştır [5].

\section{MATERYAL VE YÖNTEM}

Günümüzde elektronik röle kullanımı oldukça artmıştır. Özellikle sektörün önde gelen firmaları yüksek fiyatlara ürettikleri ürünleri satmaktadırlar. Ancak bu ürünlerin çoğu elektromanyetizma prensibine göre çalışmaktadır. Yani bunun anlamı yine röle kontakları elektromanyetik alan oluşturularak kontrol edilmekte olduğudur. Yine bu tür rölelerin bazılarında sıfır noktası geçiş sistemi kullanıldığ görülmektedir. $\mathrm{Bu}$ sistemin birçok avantajı vardır. Bunların başında elektrik sarfiyatının önüne geçilmesi, rölenin kontaklarının daha uzun ömürlü kullanılması, aşırı akımlardan ve oluşacak arklardan hem sistemin hem de çalışanın korunmasıdır. Ancak yine de röle içerisinde kontakların kullanılması hem çalışmada milisaniyeler kadar olsa da bir gecikme meydana getirilmesini sağlarken aynı zamanda kontakların aşırı akımlarda yapışması ve oluşacak arklardan dolayı bozulmasını sağlamaktadır.

Sıfır geçiş tabanlı detektörler birçok alanda kullanılmaktadır. Sıfır geçiş tabanlı detektörler; anahtarlama sistemleri [6], görüntü analizi [7], şaft titreşimlerinin açısal ölçümleri [8], hassas ultrason ölçümleri [9], rotor konumunun tespit edilmesi [10] gibi yaygın kullanıma sahiptir. Günümüzde; distorsiyonun, gecikmenin ve maliyetin en düşük olduğu sıfır geçiş tabanlı elektronik şalter çalışmaları bulunmaktadır. Vorobyov ve Vitols; optik yalıtıcı devreler [11], karşılaştırıcı devreler [12-13], işlemsel yükselteçler [14], adaptif filtre yöntemleri [15-16], yapay sinir ağları [17] sıfır geçişli detektör tiplerini distorsiyon seviyesi, gecikme ve fiyat olarak karşılaştırmıştır [18].

Yapılan çalışmada elektronik rölede elektromanyetik alan prensibine göre çalışan kontaklar yerine kullanılacak MOC serisi bir optokuplör entegresi ile bir triyağın tetiklenmesi ile akım geçişinin sağlanması gerçekleştirilmiştir. MOC serisi entegresi aynı zamanda sıfır nokta akım geçiş prensibine göre çalıştırılarak aşırı akım sonucu oluşa bilecek her türlü ark oluşumundan kaynaklanacak patlama ve yangınların önüne geçilerek hem tüm sistemin hem de çalışanın korunması sağlanmıştır [19].

Ayrıca önerilen sistemde devreye elektronik kaçak akım rölesi eklenerek şu an ülkemizde üretimi olmayan bir sistemin yapımı sağlanmıştır.

Şekil 1'de görüldüğü gibi önerilen sistem iki ayrı devreden oluşmaktadır. Birinci devre güç devresi olup sisteme gücün aktarılmasını kontrol eder. İkinci devre olan lojik devre güç devresinin kontrolünü sağlar. Lojik devrede kontrolü sağlamak için PIC serisi bir mikrodenetleyici kullanılmıştır. Güç devresinde ise ayrıca toroid bir transformatör kullanılarak kaçak akım rölesi çalışması sağlanmıştır. Ayrıca MOC serisi bir optokuplör ile AC sinyalin sıfir geçiş noktasında triyakların tetiklenmesi gerçekleştirilmiştir.

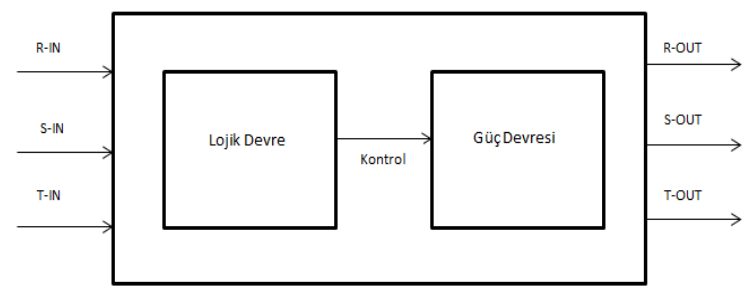

Şekil 1. Önerilen sisteme ait blok şema

\subsection{Güç Devresi}

3 Faz girişleri (R-IN/S-IN/T-IN) lojik kart üzerinde gösterilen trigger coil adlı toroidal transformatör içerisinden geçerek T1/T2-T3 triyakları ile çıkışa (ROUT/S-OUT/T-OUT) aktarılır. Her faza ait triyaklar sıfır geçiş detektörü içeren optodiyak entegresi olan MOC3041M (OK-1/OK-2/OK3) entegreleri ile sürülür. Lojik devreden optik olarak izole edilmiştir. Şekil 2'de güç devresi verilmiştir.

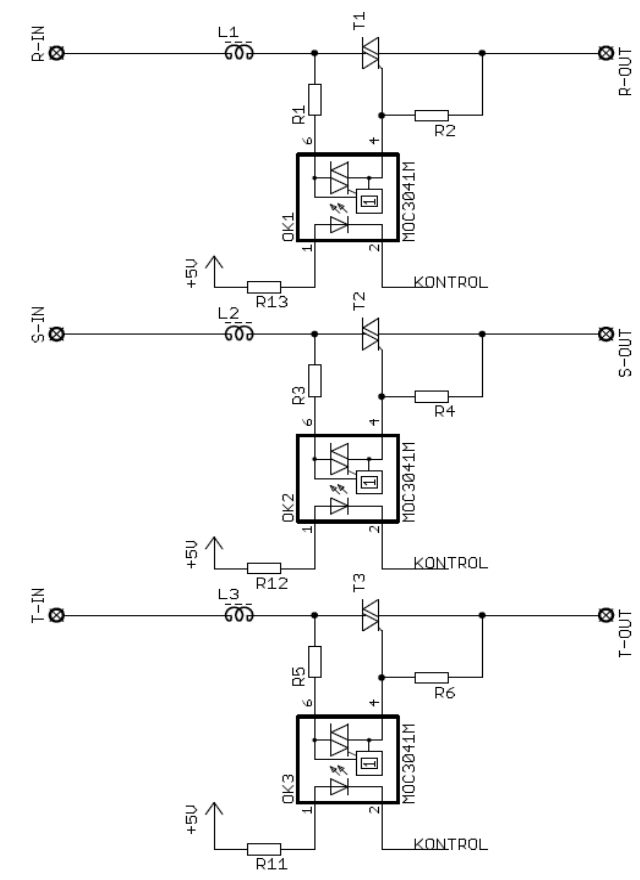

Şekil 2. Güç devre şeması 


\subsection{Lojik Devre}

Şekil 3'te lojik devre şeması görülmektedir. Devrede PIC 12C508 mikrodenetleyicisinin üç adet pini kullanılmıştır [20]. GP2 pini bağlı bir push button ile sistemin devreye alınması veya devreden çıkarılması sağlanmaktadır. GP1 pini güç katındaki L1-L2-L3 bobinlerinin de sarılı bu toroidal transformatör üzerine 0,2 mm kesitli 1200 tur trigger bobini elde edilmiştir. Böylece L1-L2-L3 bobinlerinden akan yük akımı dışında toprağa bir akım akması halinde hissedilecektir. Hata anında indüklenen bu gerilim AC olduğu için B1 köprü diyotu ile doğrultularak GP1 pinine uygulanmıştır. Mikrodenetleyiciyi aşırı gerilimden korumak için 4,7 Volt zener diyot (D1) kullanılmıştır. GP0 pini mikrodenetleyicinin kontrol çıkışıdır. Aynı anda üç adet MOC3041 tetikleneceği için NPN bir transistör ile tamponlanmıştır. Bu transistöre uygulanan pozitif tetikleme sinyali güç katındaki her faza ait optodiyakların GND pinlerinin devreyi tamamlamasını sağlar. Fakat, MOC3041 entegresi bu anda iletime geçmeyip her fazın sıfir noktasını bekler. $\mathrm{Bu}$ süre en fazla 1/100 saniye sürer. Bunun nedeni frekans1 $50 \mathrm{~Hz}$ olan AC sinyalde toplam 100 adet alternans olmasidir. Mikrodenetleyici içerisine proton programı kullanılarak yazılan kodlar ve program algoritması Şekil 4'te verilmiştir.

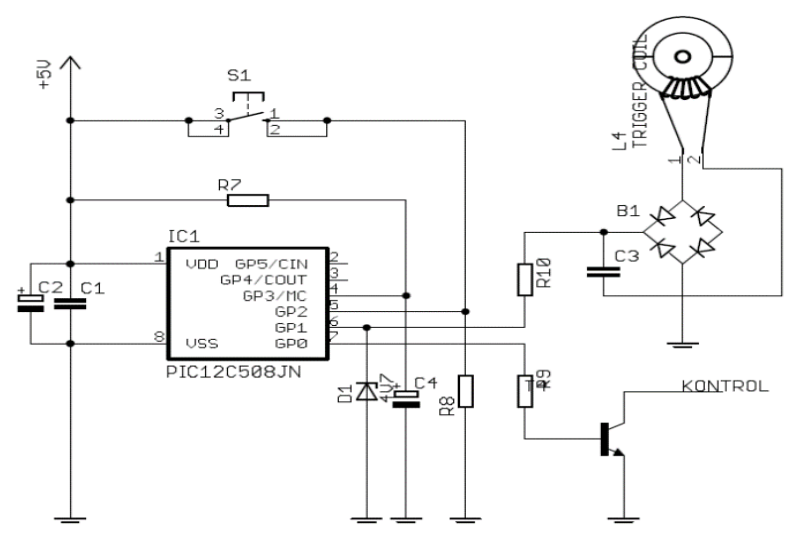

Şekil 4. Lojik devre şeması

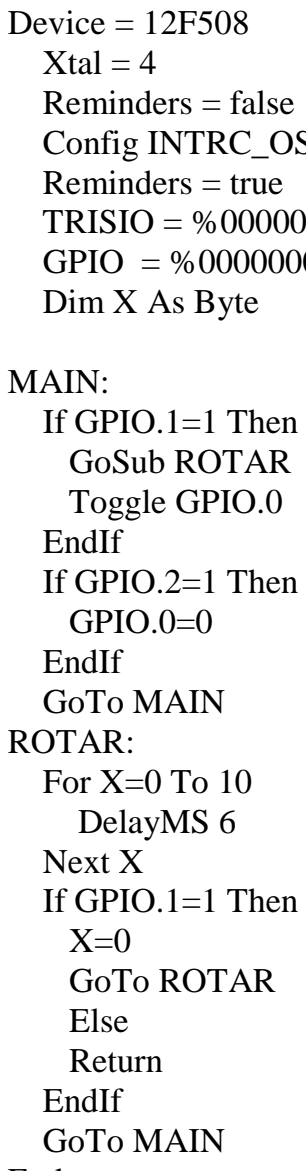

End

\section{3. Önerilen Sistemin Genel Çalışması}

3 Faz girişleri (R-IN/S-IN/T-IN) TRIGGER COIL adlı toroidal transformatör içerisinden geçmektedir. Ancak, bu durumda fiziksel bir bağlantı bulunmamaktadır. $\mathrm{Bu}$

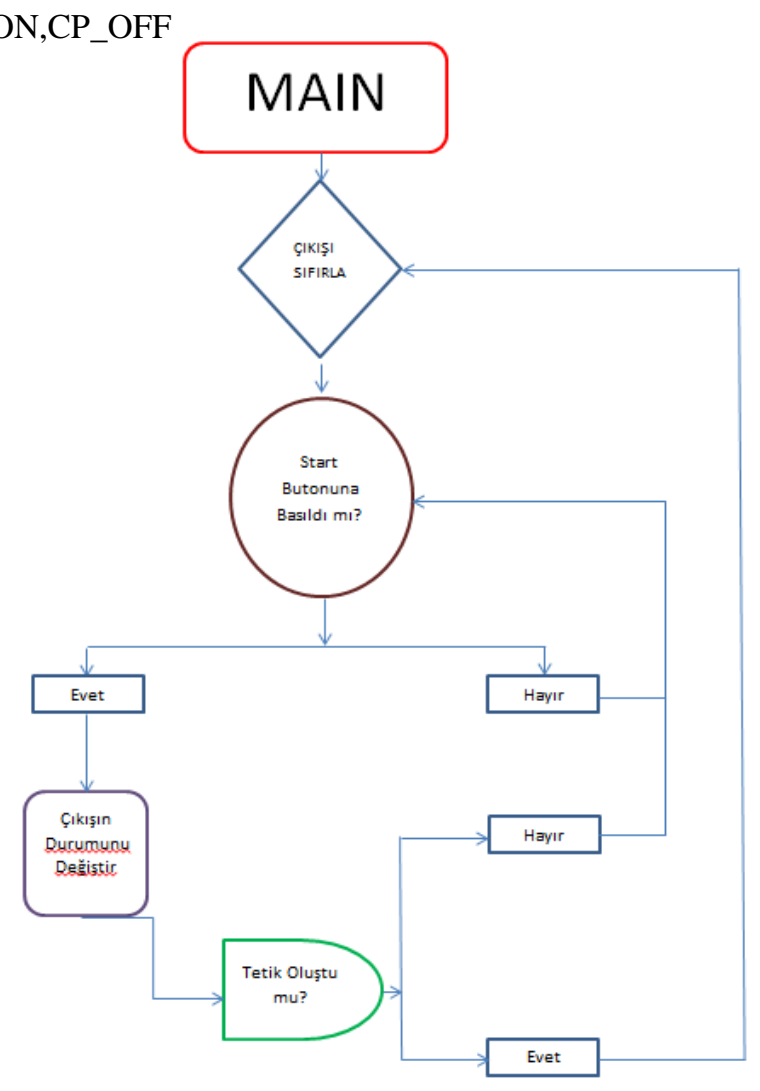

Şekil 4. Program algoritması

yapının amacı, transformatörün yapısı gereği üç faz girişlerin transformatörde oluşturacağı manyetik alanı takip etmektir. Böylece, düşük seviyelerde bile herhangi bir manyetik alan değişimi algılanıp 
transformatör tarafından mikrodenetleyiciye iletilecek ve mikrodenetleyicinin GP0 pinine bağlı kontrol çıkışı tarafından güç devresindeki MOC entegreleri kesime götürülecektir. Böylece çok hızlı çalışan elektronik bir kaçak akım rölesi sistemi kurulmuştur.

Trigger bobini adlı toroidal transformatör çıkışı köprü diyot ile doğrultularak mikrodenetleyicinin GP1 pinine bağlanmaktadır. Böylece, transformatör üzerindeki manyetik alan değişimi mikrodenetleyiciye aktarılmıştır. Devredeki mikrodenetleyici kontrolü sayesinde piyasada kullanılan rölelerinin aksine kontak kullanımına gerek kalmamıştır. Böylece, hem kontaklarda oluşacak arklar önlenerek olası yangın ve elektrik çarpmalarının önüne geçilirken hem de sinyaldeki gecikme önlenmiştir.

Lojik devrede mikrodenetleyicinin GP0 pininden çıkan sinyal yine lojik devrede gösterilen NPN tipi transistör ile tamponlanarak güç devresindeki üç ayrı MOC entegresi optodiyak uçlarına bağlanmaktadır. Böylece, MOC entegresi içerisindeki triyakların tetiklenmesi sağlanmaktadır. Herhangi bir yük akımındaki değişiklik anında kontrol çıkışı kesilecek ve MOC entegreleri kesime gidecektir. İletime geçirme esnasında ise MOC3041 entegreleri sıfir geçiş noktasını bekleyerek sisteme enerji yükleyecektir. Böylece piyasada kullanılan şalterlerin tersine hem sistem hem de can güvenliği sağlanmış olacaktır.

\section{SONUÇ}

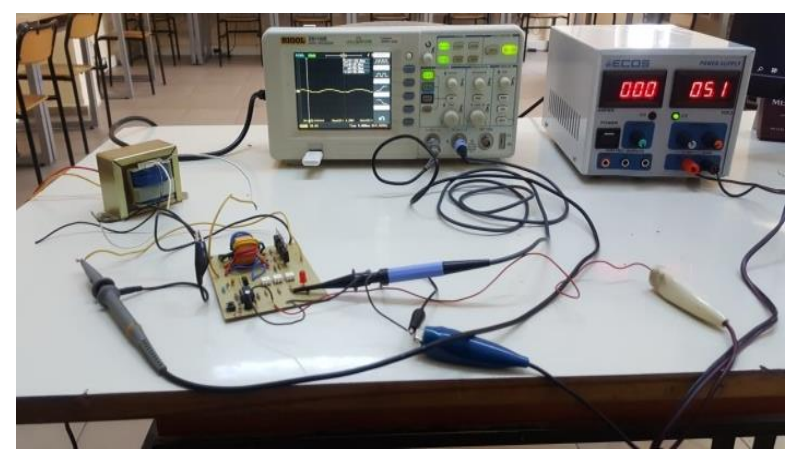

Şekil 5. Devre bağlantılarının genel görünümü

Şekil 5'te önerilen sisteme ilişkin ölçümlerinin yapıldığg devre bağlantıları görülmektedir. Önerilen sistem üç faz olup 380 Volt ve $25 \mathrm{~W}$ güce kadar çalışabilmektedir. Ancak, osiloskop ölçümlerini daha güvenli bir şekilde yapmak amacı ile tek faz üzerinden çalıştırılmıştır. Sistem girişine bir AC transformatör yardımı ile 20 Volt gerilim uygulanarak ölçümler yapılmıştır. Yük olarak devre çıkışında $100 \Omega-5 \mathrm{~W}^{\prime} \mathrm{l}_{\mathrm{k}}$ taş direnç kullanılmıştır. Mikrodenetleyici besleme sinyali olarak DC 5 Volt bir üreteç yardımı ile devreye uygulanmıştır. Yapılan ölçümlerde RIGOL DS1102E marka dijital osiloskop kullanılmıştır. Osiloskobun 1. kanalında (CH1 - sarı renkli sinyal) önerilen sistemin çıkış sinyali, 2. kanalında ( $\mathrm{CH} 2$ - mavi renkli sinyal) ise mikrodenetleyici çıkışındaki triyakların tetikleme sinyali görülmektedir.

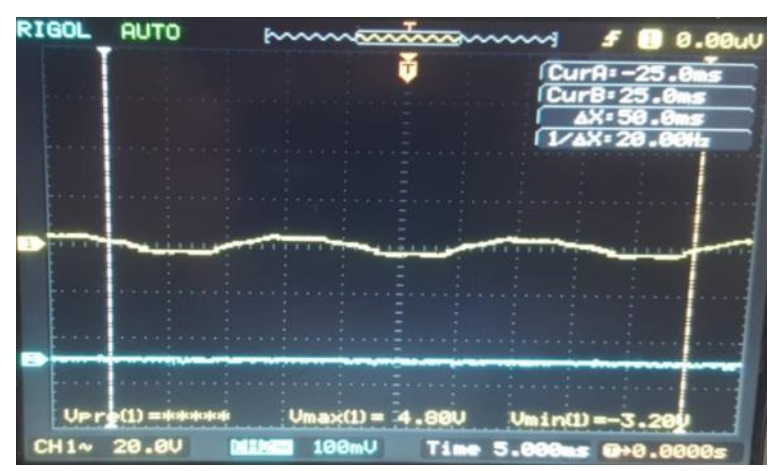

Şekil 6.Tetikleme sinyali verilmeden çıkış sinyali

Şekil 6'da devre çıkışına yük bağlı değilken ve PIC mikrodenetleyiciye tetikleme sinyali verilmeden alınan sinyaller görülmektedir. Her iki sinyalde de devreye yükün bağlı olmamasından dolayı oluşan düşük seviyeli bir distorsiyon bulunmaktadır.

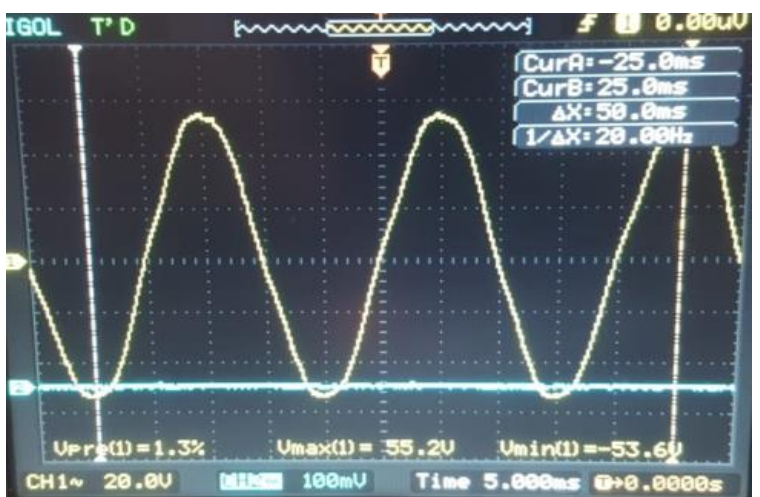

Şekil 7. Tetikleme sinyali verildiğinde çıkış sinyali

Şekil 7'de devre çıkışında yük bağlı olmadan mikrodenetleyici tarafında triyaklara tetikleme sinyali verildikten sonra alınan çıkış sinyali görülmektedir.

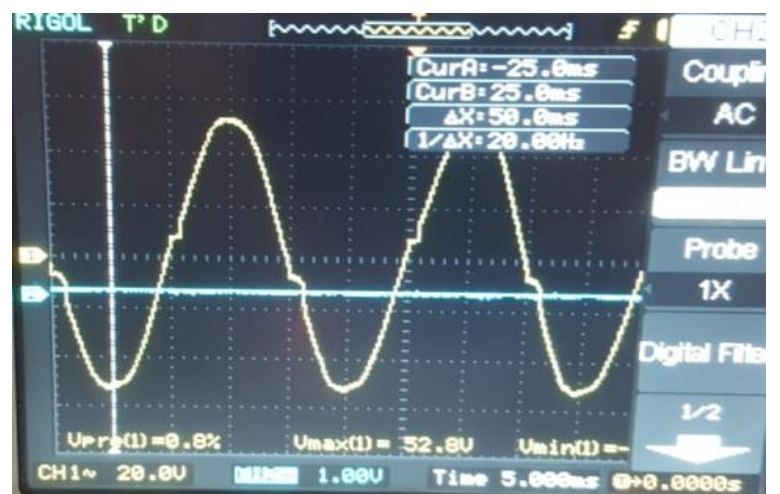

Şekil 8. Tetikleme sinyali verildiğinde çıkış sinyali

Şekil 8'de devre çıkışına yük bağlandığında mikrodenetleyici tarafından triyaklara tetikleme sinyali verildikten sonra alınan çıkış sinyali görülmektedir. Devre çıkışında yük bağlı olduğu andaki çıkış sinyalinde görülen kırılmalar transformatör ve önerilen sistemde kullanılan triyakların çalışma geriliminden daha düşük bir gerilimde ölçümlerin yapılmasından kaynaklanmaktadir. 

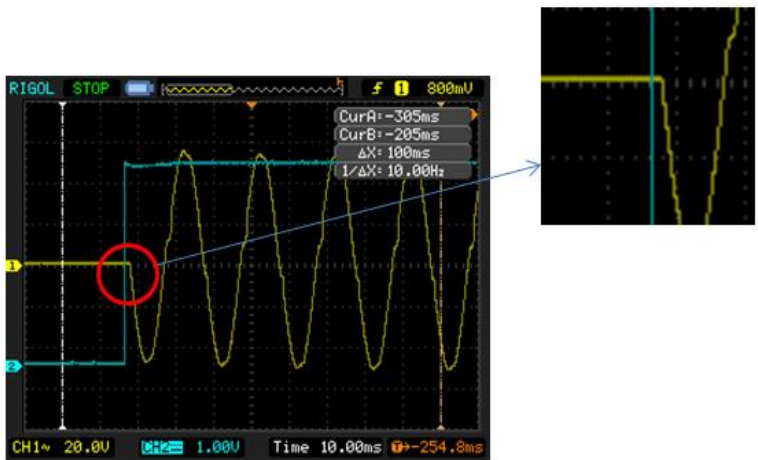

Şekil 9. Tetikleme sinyali verilme anındaki çıkış sinyalinin sıfır seviyesinde aktif olduğu an

Şekil 9'da mikrodenetleyici tarafindan tetikleme sinyalinin verildiği anda MOC3041 entegrelerinin sıfir geçiş anında triyakları tetikleyerek giriş sinyalinin sıfır noktasında devrenin çıkışına aktarıldığı açıkça görülmektedir. Tetikleme sinyalinin verilmesi ile çıkış sinyalinin aktif olması arasındaki geçen süre tetikleme sinyalinin AC sinyalin hangi noktasında verildiğine göre değişmektedir. Bu da en fazla $50 \mathrm{KHz}$ lik bir AC sinyalde yarım alternanslık süre olan $0,02 \mathrm{~ms}$ olacaktır.

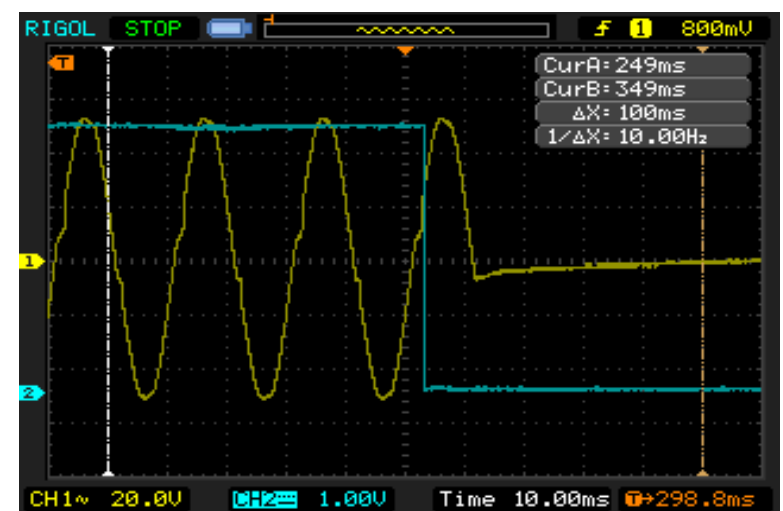

Şekil 10. Tetikleme sinyali kesilme anındaki çıkış sinyalinin sıfır seviyesinde pasif olduğu an

Şekil 10'da mikrodenetleyici tarafindan tetikleme sinyalinin kesildiği an ve triyakların kesime giderek çıkış sinyalinin kesildiği an görülmektedir. Tetikleme sinyali kesildiğinde çıkış sinyali AC sinyalin sıfır noktasında kesildiği görülmektedir.

\section{DEĞERLENDİRME}

$\mathrm{Bu}$ çalışmada elektronik şalter ve kaçak akım röleli hibrit bir sistem tasarlanmış, üretilmiş ve fiziksel olarak test edilmiştir. Önerilen sistem, güç ve lojik kısım olarak iki ayrı alt sistemden oluşmaktadır. Bu iki kısım arasında fiziksel bir bağ yoktur. Bu durumda sistemin yüksek güç gerektiren endüstriyel ortamlarda elektrik panolarında güvenli bir şekilde kullanılmasını sağlamaktadır. Önerilen sistem, hem elektronik bir şalter hem de elektronik kaçak akım rölesi barındırmaktadır.

\section{KAYNAKLAR}

[1] Akarçay, O. (2017). Elektrik İşlerinde İş Sağlığı ve Güvenliği İller Bankası A.Ş’ye Ait Bir Örnek Üzerinde İncelenmesi, Uzmanlık Tezi, Türkiye, s.1.

[2] Sosyal Güvenlik Kurumu, http://www.sgk.gov.tr/wps/portal/sgk/tr/kurumsal/i statistik, (Aralık 2019).

[3] Yılmaz, Y. ve Özbey, Ş. (2003). Kaçak akım koruma cihazları. Sakarya Üniversitesi Fen Bilimleri Enstitüsü Dergisi, 7(2), 142-145.

[4] Güner, R. (2013). Elektrikte işçi sağlığı ve güvenliğinin temel unsuru: Kaçak akım röleleri, Elektrik Mühendisliği, 447, 20-23.

[5] Ceylan, H. (2012). Türkiye'deki elektrik iletim tesislerinde meydana gelen iş kazalarının analizi, Electronic Journal of Vocational Colleges. 98-109.

[6] Zheng, G. ve Zhang, Z. (2012). A novel intelligent load control switch based on dynamic compensation method for current zero-crossing point. Advanced Materials Research, 4717-4724.

[7] Florea, L., Flore C., Vranceanu, R. ve Vertan, C. (2012). Zero-crossing based image projections encoding for eye localization. 20th European Signal Processing Conference (EUSIPCO 2012), Bucharest, Romania, 27-31 Ağustos.

[8] Addabbo, T., Biondi, R., Cioncolini, S., Fort, A., Rossetti F. ve Vignoli, V. (2014). A Zero-crossing detection system based on FPGA to measure the angular vibrations of rotating shafts, IEEE Transactions on Instrumentation and Measurement, 63(12), 3002-3010.

[9] Jobst, S. ve Bierl, R. (2014). A Comparison of correlation and zero-crossing based techniques in ultrasonic measurements, Applied Research Conf. 362-267.

[10] Sun, L. (2019). A new method for sensorless control of brushless DC motor. Cluster Computing. 22(02), 2793-2800.

[11] Wall, R. W. (2003). Simple methods for detecting zero crossing. Proceedings of the 29th Annual Conference of the IEEE Industrial Electronics Society (IECON2003), 3, 2477-2481.

[12] Elliott Sound Products, Zero crossing detectors and comparators, https://soundau.com/appnotes/an005.htm, (Aralık 2019).

[13] Rowlan, J. (2000). Differential line receivers function as analog zero-crossing detectors. Electronic Design. 142.

[14] Irmak, E., Colak, I., Kaplan, O. ve Guler, N. (2011). Design and application of a novel zerocrossing detector circuit, Proceedings of the $3 \mathrm{rd}$ International Conference on Power Engineering, Energy and Electrical Drives (POWERENG2011), 1-4, 11-13 May1s.

[15] Vainio, O. ve Ovaska, S. J. (2002). Adaptive lowpass filters for zero-crossing detectors, Proceedings of the 28th Annual Conference of the IEEE Industrial Electronics Society (IECON2002), 2, 1483-1486, 5-8 Kasim. 
[16] Vainio, O. ve Ovaska, S. J. (1996). Digital filtering for robust 50/60 Hz zero-crossing detectors. IEEE Transactions on Instrumentation and Measurement, 45(2), 426-430.

[17] Valiviita, S. (1998). Neural network for zerocrossing detection of distorted line voltages in weak AC-systems, Proceedings of the Instrumentation and Measurement Technology Conference (IMTC1998), 1, 280-285, 18-21 Mayis.
[18] Vorobyov, M. ve Vitols K. (2014). Low-cost voltage zero-crossing detector for AC-grid applications, Electr. Control Commun. Eng., 6(1).

[19] MOC 3041 Data Sheet, https://www.fairchildsemi.com/datasheets/MO/M OC3041M.pdf, (Aralık 2019).

[20]Microchip PIC 12C508 Data Sheet, https://www.microchip.com/wwwproducts/en/PIC 12C508, (Kasim 2019). 